\title{
Introduction: Evolutionary Theory and Its Applications to New World Settlement Studies
}

\author{
Rolando González-José
}

Published online: 21 May 2011

(C) Springer Science+Business Media, LLC 2011

The first descriptions of Americans were not framed on scientific grounds or according to a specific research program. Rather, they were mere beliefs and conjectures stated by fifteenth and sixteenth century Spanish explorers who joined expeditions to still unknown lands and inhabited the colonies. Many of them, like Gonzalo Fernández de Oviedo, José de Acosta, Luis de Gomara, Bartolomé de las Casas, and Bernardino de Sahagún, were fascinated with the question of the origins of Native Americans. Thus, since the epochs of Columbus and Moctezuma, curiosity about Native American origins has not only been of scientific interest. It should be viewed, to a certain extent, as one more among the many inquiries naturally posed by two cultures making contact.

Since the eighteenth century onwards, the Christian/ mystical explanations to geographic distribution of human groups started to give place to more rational, objective, and systematic approaches. The advent of well-established scientific approaches didn't started until the first American and Latin American universities directed the collection of anthropological and archeological data in a systematic manner. In sum, it was a combination of establishment of European anthropologists, the work of novel American scholars, and the accumulation of evidence that led to the first theories of human settlement of the continent. From our modern (and comfortable) point of view, many of these theories look absurd. However, these first theories were set in a scientific landscape characterized by a discouraging

\footnotetext{
R. González-José $(\bowtie)$

Centro Nacional Patagónico,

Consejo Nacional de Investigaciones Científicas y Técnicas,

Bvd. Brown 2915,

U9120ACD Puerto Madryn, Argentina

e-mail: rolando@cenpat.edu.ar
}

scarcity of data - at least as seen from our time - not only about Native American origins but also concerning the origin and evolution of humanity as a whole. Note that it was not until the second half of the twentieth century that the African origin of our lineage was utterly accepted. That is also why nineteenth and early twentieth century theories about human settlement of the continent can be classified into three noticeably different categories: those stating an in situ American origin of the humanity, those postulating a unique and recent origin for all Americans, and those suggesting a very ancient, multiple, and heterogeneous origin. It was the Argentinean paleontologist Florentino Ameghino who, based on his findings at the Monte Hermoso locality, ardently suggested that the origin of the human species should be placed in the middle Tertiary of South America (Ameghino 1921). A better examination of his archeological and anthropological findings demonstrated that the remains were quite recent, thus invalidating his whole theory. Even though the Ameghinean hypothesis fell into discredit, he was an early defender and promoter of the (by this epoch, controversial) Darwinian ideas among the community of Latin American paleontologists, anthropologists, and archeologists.

The notion of a single Asian origin for New World inhabitants was prematurely stated by the Jesuit priest José de Acosta, who in his Historia Natural y Moral de las Indias first introduced the concept (Acosta 1589). However, defenders of the single origin were known years later as the "American school" in reference to a group of U.S. scholars led by Czech anthropologist Ales Hrdlička. Their view about the settlement process included a single Asian source population for all the Americans, an entry from Asia to North America through the Bering Strait, and an in situ development of the cultural and linguistic diversification observed among modern Native Americans. According to 
Hrdlička (1925), the external (phenotypic) differences were originated previously, outside the Americas, and were not deep enough to invalidate the uniqueness of the Americans.

Conversely, some European and Latin American scientists defending the multiple origins theory agreed in denying the "racial" unity of the Americans and considered that the differences observed among different American groups were the by-product of a variable number of migratory waves originating not necessarily in Asia alone but also in Polynesia and Australia (see Canals Frau 1950; Imbelloni 1938). Their emphasis on long-range migrations of "types" or "races" gave the label of "diffusionist" to this school. Besides their fit (or lack of it) with modern state-ofthe art, these theories must be interpreted as part of the racial, typological paradigm that dominated anthropology during the nineteenth and early twentieth century. Namely, the research and interpretations' focus was on differences between human populations. In consequence, the expectation that pure regional types or races had once existed, and the quasi-infinite number of variants that the combinations of these types could have originated, was a mechanism solid enough to explain the observed variation. It is well known that this view gave a kind of scientific support to eugenic and racist movements, mainly in the U.S. and Europe, which determined much of the subsequent development of the discipline (Lahr and Foley 1998).

Opportunely, after World War II, studies of the origin of American Indians were unanimously placed in the population genetics paradigm, emphasizing the population as the unit of study, discarding "race" as a true biological entity appropriate to our species, and stressing the importance of restricted microevolutionary events (e.g., gene flow/gene drift balance) and local adaptation as the main processes generating the observed patterns of genotypes and phenotypes. This brief historical summary of the research of Native American origins is sufficient to understand why, after abandoning decades of typological views, modern scientific and popular knowledge about the facts and processes that led to the human occupation of the New World has been inundated by evolutionary theory. A rephrasing of Theodosius Dobzhansky's famous maxim is appropriate here: "Nothing in the study of the New World settlement makes sense except in the light of evolution." Archeologists, glaciologists, geneticists, paleontologists, anthropologists, and linguists working on Native Americans' history and structure exploit the vast assortment of theoretical and methodological tools that evolutionary theory provides. During the last decades, specialists dedicated to exploring the human occupation of the Americas have benefited from genomic analyses, simulation of demographic and dispersal scenarios, ecological modeling, coalescent theory, quantitative and population genetics, bio- and phylogeography, human-parasite coevo- lution, ancient-DNA techniques, geometric analyses of size and shape, phylogenetics, etc.; all can be seen as a fascinating toolbox that informs most of the recent papers shedding light on the issue in some way and fuel new rounds of debate.

This special issue shows only a limited, arbitrary sample of applications of modern evolutionary theory to infer the past of our continent and to fuel the debate around the settlement of the Western Hemisphere. But, since evolutionary anthropology is based in natural science and social science, another goal of this issue is to explain as well why some disciplines of crucial importance to understanding settlement of the New World, like archeology or biodemography, require a broader theoretical and methodological framework exceeding the limits of evolutionary biology. For instance, on many occasions, cultural determinants are transmitted in a horizontal way, thus generating patterns of variation that cannot be interpreted straightforwardly (see Tëmmkin and Eldredge 2007). This opens new and interesting challenges regarding how disciplines dealing with particular kinds of evidence (e.g., archeological, sociocultural, and linguistic) that are of crucial importance to get the full picture of a complex process take advantage of evolutionary thought and adapt it to non-biological data. Also, it is clear that evolutionary anthropology lies at the core of debate around human dispersal across the New World and that evolutionary theory integrates interpretations about past and present processes, even though the nature of the evidence often requires different methodologies (Shennan 2009).

Besides the scientific stimuli, studying human dispersal across the continent brings some academic pleasures. Because of the continent-wide nature of the process under study, scholars working on it came from a huge range of institutions in the Americas, Europe, and Asia, constituting a network formed by different disciplines but also by an international melting pot of people. It is interesting that many of the central debates around the American settlement were driven by topics originated from North American evidence. Just to cite some examples, the debate around the timing and autochthonous-ancestral character of the Clovis culture pervaded much of the archeological approaches to the settlement of the three Americas, even when no clearly assigned Clovis remains were ever found in South America, and it still permeates many of the reviews about the New World settlement (Dillehay 2009; Waters et al. 2011). Similarly, even though the record of ancient skulls is far richer and better contextualized in South America, particularly the remains from the Lagoa Santa site in Brazil (see Neves and Hubbe 2005), finding the Kennewick skull and discussion of its lack of similarity to modern Native Americans (Chatters et al. 1999) fueled much of the discussion regarding phylogenetic affinities among ancient and modern stocks. 
Although these topics are still preponderant in the literature, a careful inspection of the last 20 years' publications demonstrates that all of the involved disciplines have dedicated significant effort to researching South American human evolution as well. As a result, I feel that we are starting to enjoy a geographical but also idiosyncratic and academic equilibrium among different academies and scientific traditions.

The contributions to this special issue, in a way, reflect most of the aspects cited above. They intend to explain the settlement process in the light of evolutionary thoughts, they deal with the limitations of evolutionary theory when dealing with the archeological or biodemographic record, and they provide a good picture of the potential of methods used today.

Professor Francisco M. Salzano opens this special issue with an interesting review of different simulations and models based on a vast array of evidence (demographic, genetic, linguistic, skeletal, archeological, geological) that, collectively, help to establish some concepts that are consequently supported by different scientific disciplines and scopes.

Cristina Bayón, Teresa Manera, Gustavo Politis, and Silvia Aramayo provide an exciting description and interpretation of the Monte Hermoso archeological site on the Argentinean Atlantic coast. The Monte Hermoso site analysis supports the notion that archeology constitutes the central discipline that properly sets the scenario: the places and times where humans were present. This is an example of how a single archeological site, interpreted in the whole context, can shed light on such important topics as the contact among Pleistocene extinct megafauna and humans. Similarly, for many interesting problems in evolution, Native American origins rest as much on geographical patterns as on chronological ones, and the archeological remains give access to these.

Following with the archeological record, the paper by Luis Alberto Borrero explains why evolutionary theory contributes to understanding adaptation during the early settlement. In his view, two important theoretical approaches-human behavioral ecology (O'Connell et al. 1988) and selectionism (Dunnell 1980)-derive from evolutionary theory in general and act as a source of testable hypotheses involving data from different fields, including archeology. Furthermore, Borrero emphasizes that since adaptation occurs at the individual level, the classical averaged data studies should be complemented with evidence gathered on individuals in order to get a more complete idea of adaptive processes.

In his manuscript about Spanish colonial effects on Native American mating structure, Christopher M. Stojanowski broadly places the discussion within the realm of geneculture coevolutionary research. This is a stimulating frame- work for considering many, if not all, of the bioanthropological questions today. Focusing on an extended case study of ethnic identity transformation (ethnogenesis) involving the origin of Seminole Indians, this paper builds a strong argument in favor of the necessity of including the humanistic component when carrying on microevolutionary studies of human populations.

María Cátira Bortolini and I attempted to discuss two microevolutionary events that, in our view, are of key importance to understanding how patterns of modern variation in different types of data could have been shaped during the early phases of the dispersal across the continent. More specifically, we discuss how bottlenecks and the potential existence of an Asian-American gene flow operating in the Arctic regions well after the initial settlement would affect patterns of genetic uniparental and autosomal markers, as well as skull shape traits. Besides the benefits subsumed in the understanding of the process itself, we argue that discussing processes first rather than explaining patterns ad hoc is the best way to naturally integrate different data. More precisely, if a null hypothesis is postulated in terms of an evolutionary process acting on a population or a group of populations, then predictions about how different data would fit this hypothesis can be compared with real, observed patterns. In this way, we suggest that "model-bound" approaches (sensu Relethford 1994) are the best tool to promote integration among disciplines.

Finally, Dennis O'Rourke closes this special issue with a paper aimed at meticulously deciphering the main contradictions and concordances in American colonization models. The utility of such efforts is based on the necessity of synthesizing the enormous bulk of novel data and concomitant interpretations arising in recent years. O'Rourke does a great job of integrating novel high-resolution genetic data along with a comprehensive appraisal of early archeological sites and glacial dynamics. He shows how these novel and powerful data can modify some previously established notions regarding the timing and initial population size of the first wave or waves of migrants.

This assemblage of manuscripts provides a good sample of the vitality and complexity that different disciplines provide to the issue of the New World human occupation. In the last decade, the question of the early human settlement of the Americas has been challenged by new impressive genetic, physical anthropological, linguistic, paleontological, geological, and archeological evidence. I would argue that the fascinating amounts of evidence now available in different disciplines allows the solution of the Native American origins problem but that much remains to be done in order to reconstruct the colonization process in its early phases and in exploring more regional and finegrained settlement histories. Understanding the complexities of the dispersal of Homo sapiens across virgin 
continental landmasses is important for testing hypotheses about many aspects of human evolution.

Because we lack observational data from biological and cultural patterns operating during the origin and dispersal of the first humans, we can instead exploit the cultural and biological data collected on more contemporary groups inhabiting more restricted landscapes to test several hypotheses about migration, adaptation, extinction, stochastic processes, gene-culture coevolution, etc., operating on human groups. In this context, the American continent serves as a "natural experiment" that will bring interesting clues to extrapolate on to other regions and chronological backgrounds.

Acknowledgments I would like to express my deepest gratitude to Niles, Michelle, and Greg Eldredge for providing me the opportunity of assembling this special issue and for their support and guidance throughout the editorial work. Also, thanks are given to all the contributors that kindly submitted the results of their scientific efforts to mount this special issue.

\section{References}

Acosta J de. Historia natural y moral de las Indias. Sevilla. 1589. p 535 .

Ameghino F. Le diprothomo d'aprés Schwalbe et d'apres moi. Anal Mus Nac Buenos Aires. 1921;31:1-24.
Canals Frau S. Prehistoria de América. Buenos Aires: Ed. Sudamericana; 1950.

Chatters JC, Neves WA, Blum M. The Kennewick man: a first multivariate analysis. Curr Res Pleist. 1999;16:87-90.

Dillehay TD. Probing deeper into first American studies. Proc Natl Acad Sci U S A. 2009;106:971-8.

Dunnell RC. Evolutionary theory and archaeology. Adv Archaeol Method Theory. 1980;3:35-99.

Hrdlička A. The origin and antiquity of the American Indian. Washington, DC: Government Printing Office; 1925.

Imbelloni J. Tabla clasificatoria de los indios. Regiones biológicas y grupos raciales humanos de América. Physis. 1938;12:22949.

Lahr MM, Foley R. Towards a theory of modern human origins: geography, demography, and diversity in recent human evolution. Yearb Phys Anthropol. 1998;41:137-76.

Neves WA, Hubbe M. Cranial morphology of early Americans from Lagoa Santa, Brazil: implications for the settlement of the New World. Proc Natl Acad Sci U S A. 2005;102:18309-14.

O'Connell JF, Hawkes K, Blurton Jones N. Hadza hunting, butchering, and bone transport and their archaeological implications. J Anthropol Res. 1988;44:113-61.

Relethford JH. Craniometric variation among modern human populations. Am J Phys Anthropol. 1994;95:53-62.

Shennan S. Pattern and process in cultural evolution: an introduction. In: Shennan S, editor. Pattern and process in cultural evolution. Los Angeles: University of California Press; 2009. p. 1-20.

Tëmmkin I, Eldredge N. Phylogenetics and material cultural evolution. Curr Anthropol. 2007;48:146-53.

Waters MR, Forman SL, Jennings TA, Nordt LC, Driese SG, Feinberg $\mathrm{JM}$, et al. The buttermilk creek complex and the origins of Clovis at the Debra L. Friedkin Site, Texas. Science. 2011;331:1599603. 